\title{
Methodik und Anwendungsgebiete des genetischen Fingerabdruckverfahrens
}

\author{
Thomas Lubjubn, Manfred Schartl und \\ Jörg Thomas Epplen
}

Unter einem genetischen Fingerabdruck ( $D$ DNA-Fingerprint ${ }^{\prime}$ ) versteht man ein mit molekularbiologischen Methoden erstelltes Bandenmuster aus informationsfreien DNAAbschnitten, welches hochspezifisch für das entsprechende Individuum ist. Die Entdeckung und Weiterentwicklung des genetischen Fingerabdrucks hat innerhalb kürzester Zeit zu erheblichen Fortschritten in den verschiedenen Teildisziplinen der Biologie und Medizin geführt. Durch das Aufzeigen individueller Unterschiede im Erbgut werden mit dieser Methode Grundlagen für die Bearbeitung zahlreicher Fragestellungen geschaffen. Wir wollen in diesem Aufsatz zum einen die Methodik veranschaulichen und zum anderen einige ausgewählte Anwendungsbeispiele vorstellen, die verdeutlichen sollen, welches Potential sich hinter der Methode des "DNA-Fingerprinting" verbirgt.

\section{Erbsubstanz und Individualität}

Das Erbgut eines Menschen (Genom) besteht aus rund 7 Milliarden Informationseinheiten. Jede Informationseinheit (Nukleotid) wird dabei aus einem Zucker- und einem Phosphatmolekül sowie einer von vier verschiedenen organischen Basen (Adenin (A), Guanin (G), Cytosin (C) oder Thymin (T)) aufgebaut. Die Erbsubstanz (DNA) besteht aus einer doppelsträngigen Aneinanderrcihung

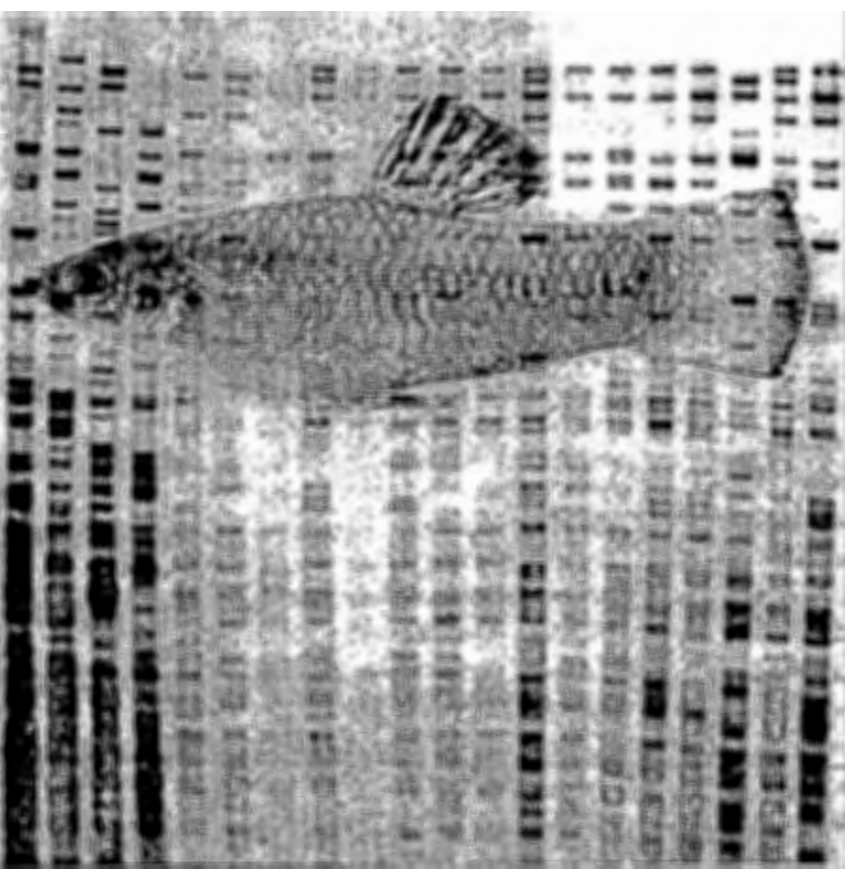

sinnvolle Abfolge von Aminosäuren ergeben, die wiederum für die Struktur und Funktion lebenswichtiger Proteine (zum Beispiel Enzyme) verantwortlich sind. Deshalb weisen entsprechende Genorte (Loci) bei verschiedenen Menschen nur eine vergleichsweise geringe Variabilität auf, das bedeutet, innerhalb solcher Regionen finden sich nur wenig Unterschiede in Bezug auf die Basenfolge. Der Grund dafür ist, daß die meisten sprunghaften Veränderungen in der Basenfolge (Mutationen), wegen der damit verbundenen Struktur- und Funktionsänderung der entsprechenden Proteine, zum Nachteil oder gar zum Tod des betreffenden Organismus führen, bevor die mutierten Gene an Nachkommen weitergegeben werden können. Genloci mit diesen sequenzabhängigen Informationen derartiger Nukleotide (Abbildung 1). Dabei ist der zweite Strang durch den ersten vorgegeben, da sich immer nur die Basen $G$ und $C$ und die Basen $A$ und $T$ zusammenlagern können (komplementäre Basenpaarung). Bei 7 Milliarden Informationseinheiten in einem diploiden, das heißt mit einem doppelten Chromosomensatz ausgestatteten Wirbeltiergenom ergeben sich so circa $10^{2000000000}$ verschiedene Anordnungsmöglichkeiten der Nukleotide. Nun kann jedoch nicht an jeder Stelle ein beliebiges Nukleotid stehen, da nur bestimmte Basenfolgen (Sequenzen) nach der Übersetzung (Transkription und Translation) der in ihnen enthaltenen Information eine machen aber nur circa 5 Prozent des menschlichen Genoms aus.

Über die biologische Bedeutung der übrigen 95 Prozent der DNA, in der keine sequenzabhängige Information enthalten ist, herrscht zur Zeit noch Unklarheit. Da der Austausch oder Wegfall eines Nukleotids, beziehungsweise die Umlagerung ganzer Sequenzteile innerhalb dieser Regionen, nicht zu einer Fehlfunktion innerhalb des Organismus führt und daher toleriert werden kann, zeichnet sich dieser Teil der DNA auf Populationsniveau durch eine wesentlich größere Variabilität aus. 


\section{Folgen der Variabilität}

Eine Anhäufung dieser Sequenzänderungen führte im Lauf der Entwicklungsgeschichte (Evolution) zu erheblichen Unterschieden in den Genomen von nicht näher verwandten Individuen einer Art. Durch eine besonders hohe Variabilität (Hypervariabilität) sind dabei die sogenannten "einfach repctitiven" Sequenzen und ihre angrenzenden Regionen gekennzeichnet. Sie sind aus einfachen, sich stetig wiederholenden Sequenzmotiven aufgebaut (beispielsweise ..GGAT GGAT GGAT GGAT..) und meist über das gesamte Genom verteilt. Das DNA- „Fingerprinting“ macht sich die Hypervariabilität und das damit verbundene hohe Individualisierungspotential dieser Sequenzen zunutze, indem es viele Sequenzblöcke aus verschiedenen Regionen des Genoms gleichzeitig darstellt ("Multilocus"-Fingerabdruck). Auf diese Weise werden Bandenmuster erzeugt, die ähnlich wie cin Fingerabdruck - ein Individuum eindeutig kennzeichnen und außcrdem nach den Mendelschen Regeln vererbt werden.

\section{Von der Zelle zum „genetischen Fingerabdruck"}

Seit der Entwicklung des DNA-„Fingerprinting" durch die Gruppe um Alec Jeffreys [1] wurde diese Methode teilweise vereinfacht und weiterentwickelt. Insbesondere die Entwicklung von Oligonukleotid-Sonden (beispielsweise $(\mathrm{CA})_{y}=$ CACACACACACACACA) [2] ebnetc den Weg zur Darstcllung individualspezifischer Bandenmuster in allen untersuchten Pilz-, Pflanzen- und Tierspezies. Die folgende kurze Darstellung der Verfahren, die zur Darstellung eincs genetischen Fingerabdrucks durchlaufen werden (Abbildung 2), beschränkt sich auf die Verwendung solcher Sonden. Der interessierte Leser sci an dieser Stelle außerdem auf eine ausführlichere Beschreibung der Methodik in der Literatur hingewiesen [3].

\section{Isolieren, Schneiden und Auftrennen der DNA}

Zur Isolierung der benötigten DNA eignen sich alle Gewebe oder Zellen, dic Zellkerne enthalten. Dabei ist es gleichgültig, ob sie aus Blut, Sperma, Urin, Speichel, Haarwurzeln oder einem beliebigen Gewebe stammen. Die DNA wird nach den für die einzelnen Zelltypen optimierten Verfahren isoliert [4]. Danach wird sic mittcls eines DNA-spaltenden En-

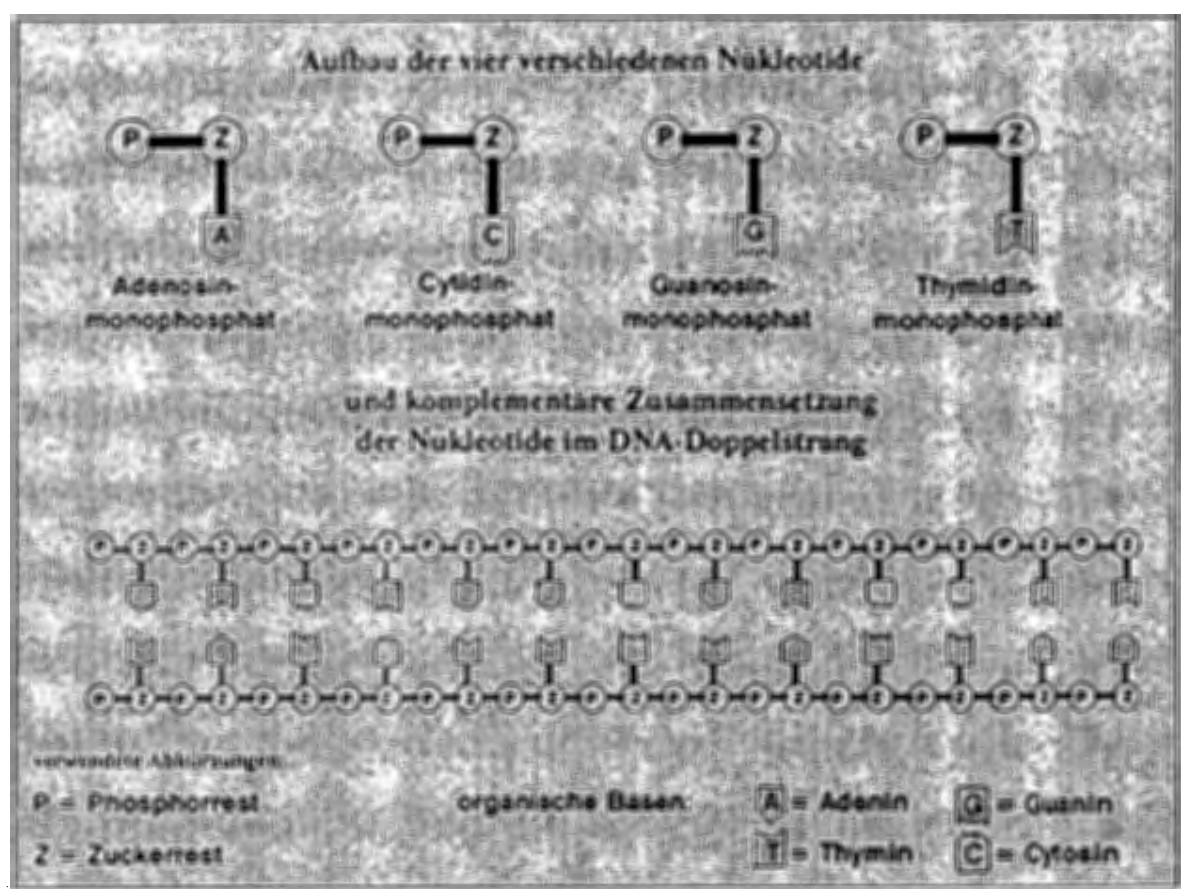

Abb. 1. Schematischer Aufbau der DNA. Im Zellkern ist der DNA-Doppelstrang zusätzlich noch schraubig gewunden (Doppelhelix).

zyms (Restriktionsendonuklease) „verdaut“. Diese Enzyme erkennen bestimmte DNASequenzen und durchtrennen den DNADoppelstrang an dieser Stelle. So erkennt die Restriktionsendonuklease $\mathrm{Hae}$ III die Sequenz GGICC und schneidet sie wie mit dem Pfeil dargestellt. Durch diesen "Verdau“ erhält man DNA-Fragmente unterschiedlicher Länge. Diese Fragmente werden anschlicßend mittels Agarose-Gelelektrophorese aufgetrennt. Dabei macht man sich den Umstand zunutze, daß DNA-Fragmentc unterschiedlicher Länge verschieden schnell durch ein Gel wandern: Die DNA-Fragmente sind aufgrund ihrer molekularen Struktur negativ geladen. Legt man eine elektrische Spannung an ein Gel, das man sich am besten als ein engmaschiges dreidimensionales Gitternetz. vorstellt, so wandern die cinzelnen Fragmente in dem elektrischen Feld aufgrund ihrer unterschiedlichen Länge verschicden weit in das Gel, da lange Fragmente nicht so schnell durch das engmaschige Gitter wandern können wie kürzere. DNA-Fragmente lassen sich also auf diese Weise entsprechend ihrer Länge auftrennen.

\section{Entstehung des genetischen Fingerabdrucks}

Nach der Elektrophorese wird die DNA im Gel fixiert. Dies geschieht, indem dem Gel durch Anlegen eines Vakuums das Wasser entzogen wird. Anschließend wird der DNA-Doppelstrang durch Behandlung mit einem alkalischen Reagens in seine Einzelstränge zerlegt (Denaturieren). Um in der Vielzahl der Fragmente diejenigen sichtbar zu machen, die bestimmte einfach repetitive Rcgionen enthalten, wird eine Oligonukleotidsonde (kurzer DNA-Einzelstrang, circa 15 bis 25 Basenpaare lang), dic komplementär zu den Zielregionen ist, zu dem $\mathrm{Gcl}$ gegeben. Diese Sonden müssen vorher markicrt werden, um sie nach der Anlagerung an die DNA nachweisen zu können. Die Markierung erfolgt meist noch mittels radioaktiver Phosphorisotope $\left.{ }^{32} \mathrm{P}\right)$. Es existieren mittlerweile aber auch nicht-radioaktive Verfahren, die mit Farbreaktionen oder Chemolumineszenz arbeiten. Die markierten Sonden lagern sich während der sogenannten Hybridisierung an die ihnen komplementären Stellen der DNA 


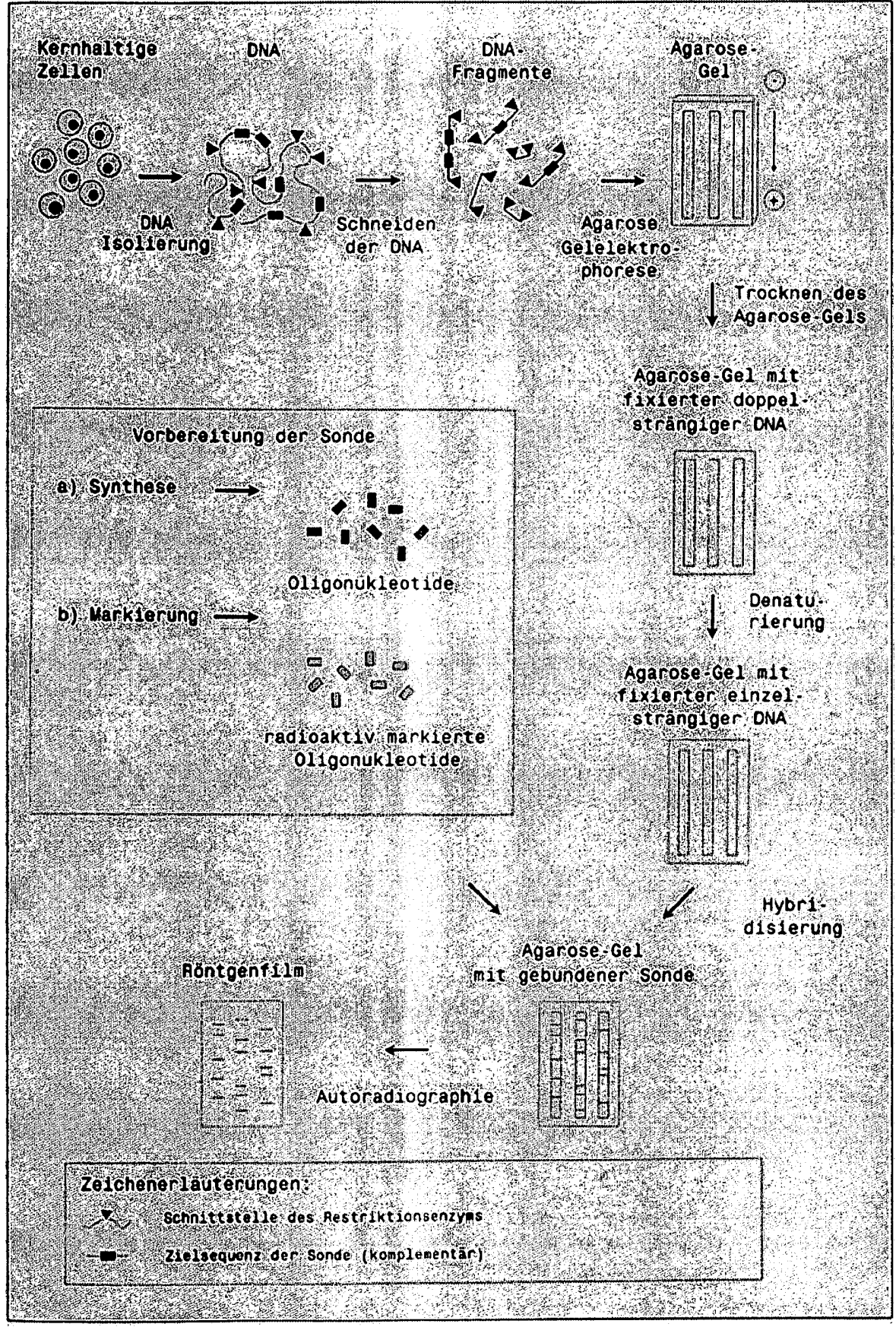

Abb. 2. Schematische Darstellung der Vorgehensweise beim Oligonukleotid-„Fingerprinting “ (siehe auch Text). an. Danach wird überschüssiges Sondenmaterial durch mehrmaliges Waschen entfernt. Anschließend werden die Stellen, an denen sich die Sonde angelagert hat, mittels einer für die jeweilige Markierung spezifischen Methode nachgewiesen. Dies geschicht im Fall der radioaktiven Markierung durch das Auflegen eines Röntgenfilms, der an diesen Stellen durch die radioaktive Strahlung der gebundenen Probe geschwärzt wird (Autoradiographie). Dadurch entsteht auf dem Film ein komplexes Bandenmuster (Abbildung 3). Bei der Wahl geeigneter Kombinationen von Restriktionsendonukleașe und Sonde sind diese Muster individualspezifisch, das heißt, alle Individuen einer Art weisen verschiedene Bandenmuster auf und lassen sich daher eindeutig identifizieren. Die einzige Ausnahme bilden hierbei natürlich eineiige Zwillinge beziehungsweise Mehrlinge. Sie sind genetisch identisch und weisen deshalb auch in den hypervariablen Regionen des Genoms keine Unterschiede auf.

\section{Die „Fingerprint“-Bandenmuster halten sich an die (Mendelschen) Regeln}

Die mit Hilfe des DNA-„Fingerprinting“ erzeugten Bandenmuster folgen außerdem den Mendelschen Regeln: Mit Ausnahme vereinzelt auftretender Mutationen läßt sich das Bandenmuster eines Nachkommen aus den Bandenmustern der Eltern zusammensetzen. Dabei geben beide Eltern durchschnittlich $\mathbf{5 0}$ Prozent ihrer Banden an ihr Kind weiter. Welche Restriktionsenzym/Sonden-Kombination ein informatives, individuelles Bandenmuster in der untersuchten Art liefert, muß im Einzelfall durch Ausprobieren ermittelt werden. Gute Anhaltspunkte ergeben sich jedoch häufig schon, wenn man bereits untersuchte Arten der gleichen Ordnung oder Gattung betrachtet. Damit können oft die in Frage kommenden Kombinationen eingegrenzt werden. Das beschriebene Ollgonukleotid„Fingcrprinting“ konnte bisher auf jede untersuchte Eukaryotenart übertragen werden. Insgesamt wurden bisher über 300 Arten aus allen Bereichen der Eukaryoten (Protoctisten, Pflanzen, Pilze und Tiere) untersucht.

\section{"Multi-Locus"- und "Single- Locus"-Sonden}

Man kann auch Sonden verwenden, mit denen nicht viele Genloci gleichzeitig ( Locus"-Sonden), sondern nur ein einzelner Locus ("Single-Locus"-Sonden) nachgewie- 


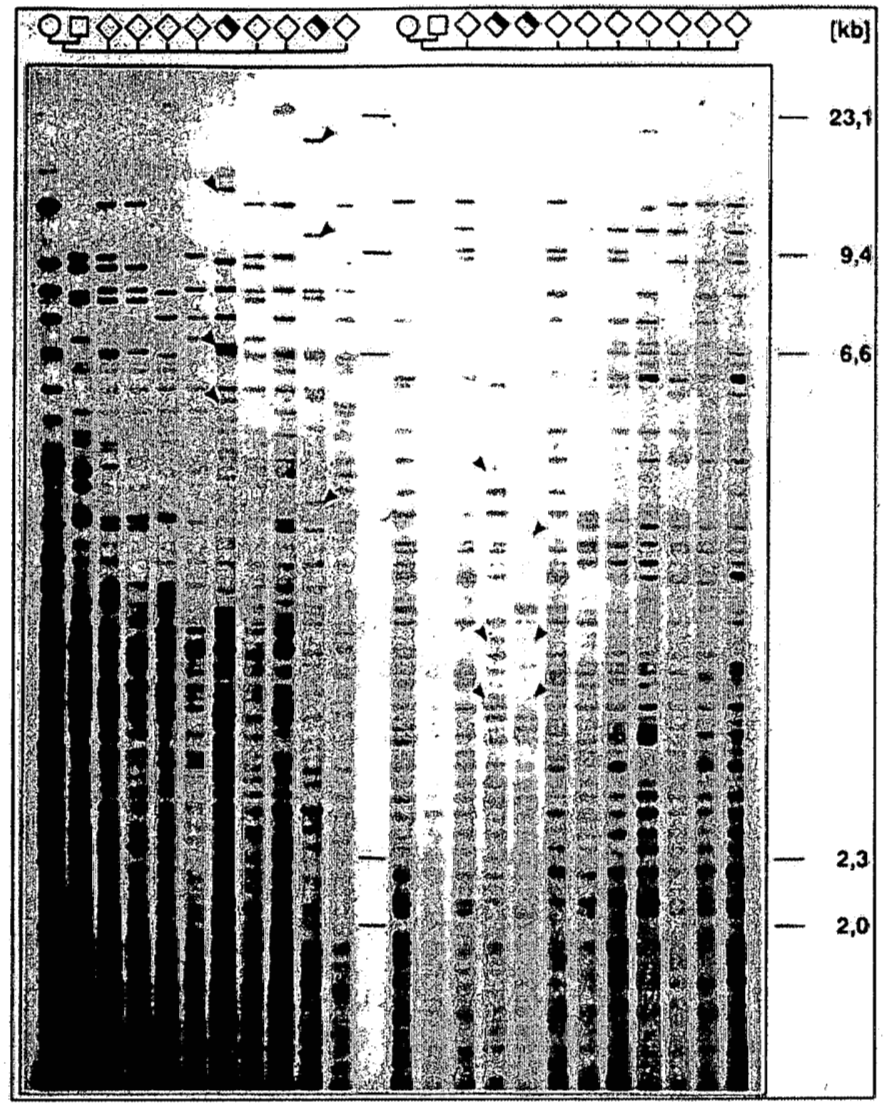

Abb. 3. Genetischer „Multilocus“-Fingerprint zweier Kohlmeisenfamilien. Die meisten Kinder ( 0$)$ stammen von ihren "sozialen" Eltern ab. Wie man aber erkennen kann, lassen sich die Bandenmuster von jeweils zwei Nachkommen ( ) nicht komplett aus den Bandenmustern der beiden Eltern ableiten. Sie weisen eine hohe Übereinstimmung mit dem Bandenmuster des Weibchens $(O)$ auf, nicht jedoch mit dem des vermuteten Vaters $(\square)$. Im Gegensatz zu den anderen Nachkommen weisen sie zusätzliche Banden auf, die bei keinem der beiden " sozialen" Eltern zu finden sind (einige dieser Banden sind in der Abbildung durch einen Pfeil gekennzeichnet). Diese Nachkommen sind daher auf Kopulationen ihrer Mutter mit einem jeweils anderen Männchen zurückzuführen. Die an der rechten Seite angegebenen Molekulargewichte entsprechen den in der mittleren Spur eingezeichneten Banden. Mit ihrer Hilfe läßt sich die Länge der einzelnen Fragmente abschätzen.

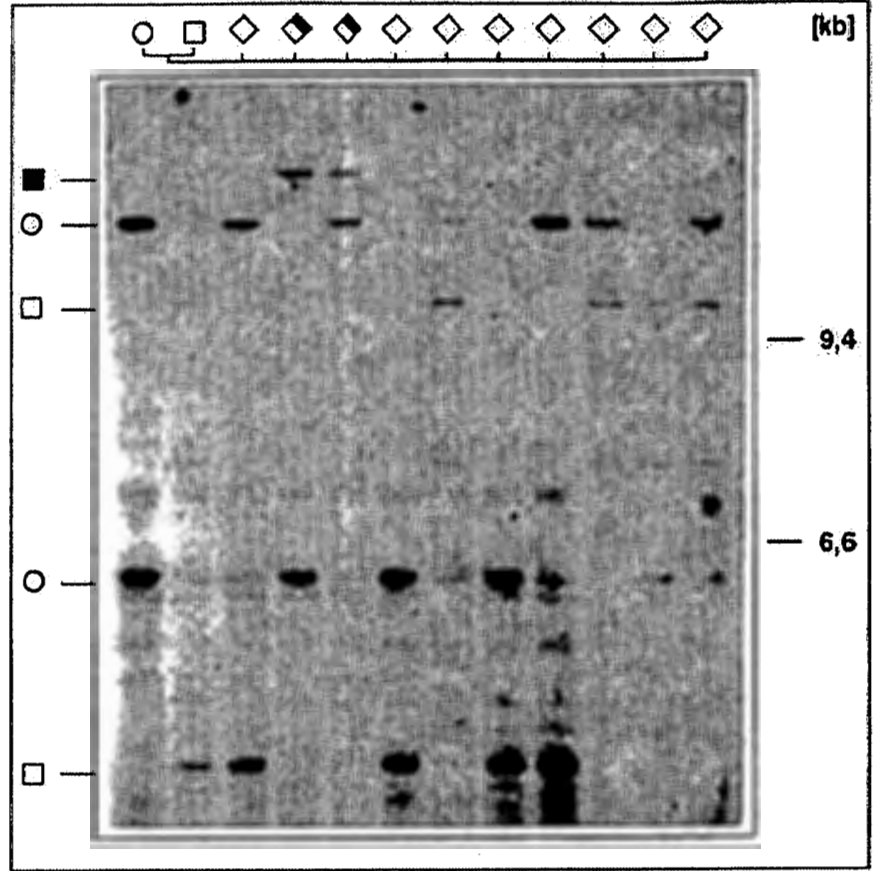

Abb. 4. Analyse eines einzelnen DNA-Locus bei einer Kohlmeisenfamilie. Das Zweibandenmuster jedes Nestlings ( $\diamond)$ muß sich aus einem mütterlichen $(O)$ und einem väterlichen $(\square)$ Allel zusammensetzen. Auch hier finden sich zwei Jungtiere $(\theta)$, die keines der beiden väterlichen Allele tragen und von daher auf Fremdkopulationen der Mutter $(O)$ mit einem anderen als dem hier gezeigten Männchen ( $\square$ ) zurückzuführen sind. Das Allel, das von diesem Männchen weitergegeben wurde, ist - wie die anderen Allele auch - am linken Rand dargestellt ( $\square$ ). An der rechten Seite finden sich, wie schon in Abbildung 3, Angaben zum Molekulargewicht. sen wird. Das sehr komplexe Vielbandenmuster reduziert sich dann auf höchstens zwei Banden pro Individuum, wobei eine Bande einem der beiden väterlichen und dic anderc einem der beiden mütterlichen DNA-Loci (Allele) entsprechen muß. Auch solche Systeme können hochvariabel sein (Abbildung 4). Die Darstellung cinzelner Allele wird leider fälschlicherweise oft auch als genetischer Fingcrabdruck bczeichnct. Einzelne Allele würden aber - in Analogic zum Fingerabdruck - nur einer einzelnen Hautlinie der Fingerbeere entsprechen und liefern somit nur einen Bruchteil der Informationen des ganzen „Multilocus“-Fingerabdrucks.

\section{Der genetische Fingerabdruck in der Anwendung}

Eines der umfangreichsten Anwendungsgebicte des DNA- "Fingerprinting" haben wir bereits angesprochen: die Elternschaftsnachwcise. Im Durchschnitt vererbo jeder Elternteil, wie bereits erwähnt, die Hälfte seiner "Fingerprint"-Banden an jedes Kind. Wie in Abbildung 3 und 4 zu erkennen ist, lassen sich hier dic Bandenmuster einzclner Nachkommen (in diesem Fall handelt es sich um Nestlinge von Kohlmcisen) nicht aus den Bandenmustern der Eltern zusammensetzen: In dem in Abbildung 3 dargestellten „Multi-
locus"-Fingerabdruck zeigt sich, daß das Bandenmuster dieser Nestlinge $(0)$ eine hohe Übereinstimmung mir dem Bandenmuster der Mutter (O) aufwcist, nicht jedoch mit dem ihres "sozialen Vaters" ( $\square$ ). Außerdem enthalten ihre genetischen Fingerabdrücke einige Banden, die bei keinem der beiden "sozialen Eltern" zu finden sind. Daraus läßr sich folgern, daß sie auf eine Paarung ihrer Mutter mit einem anderen Kohlmeisenmännchen zurückzuführen sind. Derartige Befunde sind in der Soziobiologie von erheblicher Bedeutung. Die Soziobiologic versucht die Evolution verschiedener Verhaltensweisen in Hinblick auf ihren Anpassungswert zu verstchen. 
Unter einer angepaßten Verhaltensweise versteht man dabei ein Verhalten, das dazu führt, die Anzahl der Nachkommen zu maximicren. Um Untersuchungen in dicsem Bereich durchführen zu können, ist es daher von außerordentlichem Interesse, den Fortpflanzungserfolg (also die Zahl der Nachkommen) eines Individuums eindeutig feststellen zu können. Dies wurde erst durch die Entwicklung des DNA- „Fingerprinting“ mit ausreichender Genauigkeit möglich. Durch die Anwendung dieser Methode konnten schr schnell neue Erkenntnisse gewonnen werden. So konnte man zum Beispiel für die eben erwähnten Kohlmcisen zeigen, daß Männchen, die von ihrem Weibchen betrogen wurden, weniger fürsorglich bei der Aufzucht der Jungtiere sind als Männchen, die nicht betrogen wurden [5].

Auch bei der Untersuchung von Rangordnungen in Zusammenhang mit dem Fortpflanzungserfolg einzelner Individuen konnten neue Erkenntnisse gewonnen werden. Bisher ging man generell davon aus, daß ranghohe Tiere für die z.usätzlichen Aufwendungen, die mit der Vertcidigung des hohen Ranges verbunden sind, durch eine höhere Anzahl an Nachkommen "entlohnt" würden. $\mathrm{Daß}$ dies, zumindest unter bestimmten Bedingungen, nicht der Fall ist, zeigt unter anderem cine neuere Untersuchung an Fischen: Es konnte gezeigt werden, daß der Fortpflanzungserfolg des ranghöchsten Tieres ( $\alpha$ Männchen) in größeren Gruppen auf Null fällt [6]. Eine Erklärung für dieses Phänomen konnte man bisher nicht finden. Diese Untersuchung machte deutlich, daß der oben erwähnte Zusammenhang - zumindest in dieser allgemeingültigen Form - nicht aufrechterhalten werden kann.

\section{Vaterschaftsnachweise mit Hilfe des DNA-„Fingerprintings"}

Elternschaftsnachweise sind natürlich nicht nur in der Soziobiologic von Intercsse. Es sei hicr nur an die vielen Vaterschaftsklagen crinnert, mit denen sich dic Gerichte auscinanderzusetzen haben. Durch die in dicsem Bercich bisher verwendeten Methoden, wic zum Beispiel Blutgruppenuntersuchungen, konnte man cigentlich nur Personen von der Vaterschaft ausschließen. Ohnc größten Aufwand war es jedoch nicht möglich, den wirklichen Vater zweifelsfrei festzustellen. Mit Hilfc der Methode des DNA- ${ }_{n}$ Fingcrprinting" ist man nun jedoch in der Lage, derartige Zuordnungen praktisch zweifelsfrei durchzuführen.
Solche Abstammungsuntersuchungen sind für die Gerichte nicht nur in Bczug auf Vaterschaftsklagen beim Menschen von Bedeutung. So wird zum Beispiel auch dic Abstammung wertvoller Pferde mittels des DNA"Fingerprinting" überprüft (im Jahr 1993 sollen 10 Prozent aller neugeborenen Fohlen erfaßt werden) oder, im Bereich des Artenschutzes, die Abstammung seltener Tiere (bei denen oft genug behauptet wird, es seien legale Nachzuchten, obwohl es sich um illegal eingeführte Wildfänge handelt) [3].

\section{Aufklärung von Straftaten}

Für die Gerichte ist neben den Abstammungsnachweisen auch die Möglichkeit der eindeutigen Identifizierung bestimmter Menschen oder Tiere mittels des genetischen Fingerabdrucks von großer Bcdcutung: Schon kleinste Mengen an DNA (rund 3 Mikrogramm) reichen aus, um einen genetischen Fingerabdruck herzustellen. Dies und die Tatsache, daß es sich bei der DNA um cin rclativ stabiles Molckül handelt, macht die Analyse von Spurenmaterial bei der Verfolgung von Straftaten möglich. So können zum Beispicl getrocknete Blutflecke, Speichel- und Spermareste oder Vaginalsekret mit Hilfe des DNA- „Fingerprinting“ untersucht werden. Die so erhaltenen Bandenmuster können dann mit denen verdächtiger Personen verglichen werden. Dadurch konnten Mordfälle in England und Dcutschland aufgeklärt werden [7]. Mit dieser Methode werden auch bei der Identifizierung von Brandleichen und von abgetrennten Gliedmaßen (zum Bcispicl nach Flugzeugabstürzen) Erfolge erzielt, ebenso bei der Aufklärung von Diebstählen (beispiclswcisc bei der Identifizicrung seltener Tiere, die aus zoologischen Gärten entwendet wurden).

Dic Möglichkeit der eindeutigen Identifizicrung anhand der Bandenmuster des genetischen Fingerabdrucks wird jedoch nicht nur bei der Verbrechensaufklärung genutzt. Bei der Herstellung von Antikörpern und Medikamenten muß zum Beispiel die Identität von Zellkulturen fortwährend überprüft werden. Dies kann auf sehr einfache, sichere und schnelle Weise mit Hilfe des DNA-„Fingerprinting" geschehen.

\section{DNA- „Fingerprinting” in der Krebsforschung}

Zum Schluß wollen wir noch cinen - zur Zcit teilweise noch in der Entwicklung befindlichen - Anwendungsbereich vorstellen. Er liegt in der medizinischen Diagnostik. Die durch das DNA- ${ }_{n}$ Fingerprinting" erzeugten Bandenmuster eines Individuums zeichnen sich dadurch aus, daß es unerheblich ist, von wclchem Gewebetyp die Zellen stammen: Es ergibt sich immer das gleiche Bandenmuster, egal ob man die benötigte DNA aus Blut, Spcichel, Muskelgewebe oder Haut isoliert hat. Ganz anders aber verhält es sich bei bösartigen Tumoren des Menschen: Innerhalb von Tumorzellen kommt es häufig zu Chromosomenmutationen oder gar zum Verlust ganzer Chromosomen. $\mathrm{Da}$ mit Hilfe der DNA- „Fingerprint"-Analyse ein Abbild des gesamten Chromosomensatzes gewonnen wird, spiegeln sich Veränderungen der Chromosomen von Tumorzellen in einer Veränderung des ansonsten immer stabilen Bandenmustcrs wider [8]. Neben Fortschritten in der Diagnostik erhofft man sich durch die Anwendung und Weiterentwicklung dieser Methode neue Erkenntnisse über die Zusammenhänge der Tumorentstehung, der Weitercntwicklung von Tumoren und der Absicdlung von Tochtergeschwülsten (Metastasenbildung).

\section{Moralische und ethische Verpflichtungen}

Wie allgemein im Themenkreis der Gentechnologic wurden in der öffentlichen Diskussion anfänglich auch Bcdenken gegen den genetischen Fingerabdruck geäußert. In Unkenntnis der Zusammenhänge fürchteten gar vercinzclt einige Juristen, daß in den innersten Kernbercich der Persönlichkeit des Individuums eingedrungen werden könne (Stichwort: "gläserner Mensch“). Bci der Verwendung von "Multilocus"-Sonden besteht diese Gcfahr jedoch nicht, da lediglich die Längeninformationen anonymer DNA-Fragmente miteinander verglichen werden, nicht aber deren Sequenzinhalt. Selbst bei einer (technisch kaum möglichen) Untersuchung des Sequenzinhaltes könnten keine Informationen über Mcrkmalc oder Vcrhaltensweisen eines Individuums gewonnen yerden, da die verwendeten DNA-Sonden sich gerade an die Stcllen des Genoms anlagern, in denen keinc scquenzabhängige Information enthalten ist. Etwas anders ist die Situation bei „Einzcllocus"-Systemen: Aufgrund der genetischen Kopplung könnten bestimmte Allele über benachbarte Genorte Wahrschcinlichkcitsaussagen rulassen. Dicse Information wird im "Multilocus"-Fingerabdruck verschleicrt, da keine Bande einem bestimmten genetischen Ort \%ugeordnet werden kann. Der Daten- 
schutz ist also in den „Multilocus“--Fingerabdruck unmitrelbar eingebaut. Dennoch ist ein Mißbrauch auch beim "Multilocus"-Fingerabdruck denkbar: Es wärc beispielsweise möglich, ein Gel nachträglich mit einer weiteren Sonde zu hybridisieren, dic an cine spezifische Gensequenz bindet und damit cin bcstimmtes Merkmal nachweist. Deshalb ist es norwendig, an die Untersuchung von menschlichem Material bestimmte Auflagen zu knüpfen. Dazu gehört, daß nur ausgewählte Institute mit der Durchführung dieser Analysen betraut werden und da $B$ dic sorgfältige Materiallagerung und -vcrnichtung sowie die Einhaltung der Vorschriften des Datenschutzgesetzes sichcrgestellt sind.

\section{Zusammenfassung und Ausblick}

Seit der Entwicklung des genetischen Fingerabdrucks hat die Zahl der Anwendungsgebiete rapide zugenommen. Das Verfahren wird mittlerweile in den verschiedensten Teildisziplinen der Biologie und Medizin angewendet. Die in diesem Aufsatz bchandelten Anwendungsbcispicle stellen hierbei nur cincn Aus schnitt der bereits verwirklichten Möglichkeiten dar. $\mathrm{Da}$ es sich um eine noch relativ „junge" Methode handelt, sind mit Sicherheit jedoch noch nicht alle Möglichkeiten ausgeschöpft: Erst die Zukunft wird zeigen, welches Potential sich wirklich hinter dem Begriff DNA-_Fingerprinting" verbirgt.

\section{Danksagung}

Wir möchten an dieser Stelle der Deutschen Forschungsgemeinschaft und der VW-Stiftung danken, die diesen Aufsac7. durch die Unterstützung einzclner Projekte teilweisc mit ermöglicht haben.

\section{Literatur}

[1] A.J. Jeffreys, V. Wilson, S.L. Thein (1985) Individual-specific 'fingerprints' of human DNA. Nature 316, 76-79.

[2] S. Ali, C.R. Müller, J.T. Epplen (1986) DNA fingerprinting by oligonucleotide probes specific for simple repeats. Hum. Genet. 74, 239-243.

[3] J.T. Epplen (1992) The methodology of multilocus DNA fingerprinting using radioactive or nonradioactive oligonuclcotide probes specific for simple repeat motifs. In: A Chrambach, M.J. Dunn, B.J. Radola (Hrsg.) Advances in elektrophoresis, Vol. 5, VCHVerlagsgescllschaft, Weinheim, 59-112.
[4] J. Sambrook, E.F. Fritsch, T. Maniatis (1989) Molecular cloning; A laboratory manual. 2. Aufl., Cold Spring Harbor Laboratory Press, New York.

[5] T. Lubjuhn, E. Curio, S.C. Muth, J. Brün, J.T. Epplen (im Druck) Influence of extrapair paternity on parental care in great tits (Parus major). In: S.D.J. Pena, R. Chakraborty, J.T. Epplen, A.J. Jeffrcys (Hrsg.) DNAFingerprinting: State of the science. Birkhäuser Verlag, Basel.

[6] M. Schartl, S. Erbclding-Denk, S. Hö]ter, I. Nanda, M. Schmid, J.H. Schröder, J.T. Epplen (im Druck) Reproductive failure of the dominant males in a pocciliid fish species, Limia perugiae. Proc. Natl. Acad. Sci. USA.

[7] L. Roewer, P. Nürnberg, E. Fuhrmann, M. Rose, O. Prokop, J.T. Eppler (1990) Stain analysis using oligonucleotide probes specific for simple repetitive DNA sequences. Forensic Sci. Internatl. 47, 59-70.

[8] J.T. Epplen, S. Bock, P. Nürnberg (1993) Tumor genome screening by multilocus DNA fingerprints as obtained by simple repetitive oligonucleotide probes. In: C. Wagner, R. Neumann (Hrsg.) Molccular diagnostic of cancer, Springer, Berlin, 41-51.

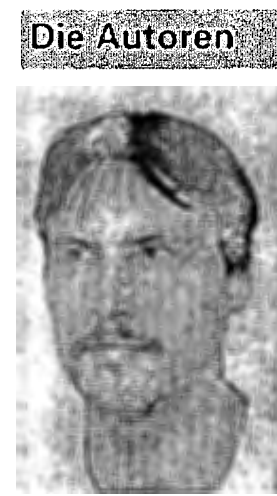

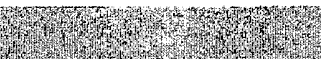

Thomas Lubjuhn, geb. 1962 in Alpen; 19841989 Studium der Biologic in Bielefeld (Bercich: Stoffwechselphysiologic); scit Oktober 1989 Promotion über verschiedene Fortpflanzungsstrategien bei Vögeln in der Arbeitsgruppe für Verhaltensforschung (Fakultät für Biologie) an der Ruhr-Universität Bochum.

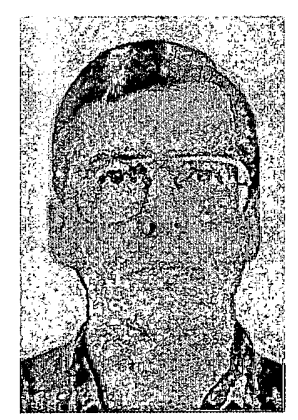

Manfred Schartl, geb. 1953 in Fricdberg' Hessen; Studium der Biologic und Chemie an der Justus-LiebigUniversität Gießen; 1978 Diplom in Biologie; 1979 Staatsexamen (L3) in Biologic und Chemic; Promotion 1980 in Gießen; Habilitation 1988 für das Fach Zoologie an der Ludwig-Maximilians-Universität München;
1980-1984 wissenschaftlicher Assistent und Hochschulassistent am Genetischen Institut in Gießen; 1985-1991 Arbcitsgruppenleiter am Genzentrum des MPI für Biochemie in Martinsried; seit 1991 Professor für Physiologische Chemic an der Universität Würz.burg.

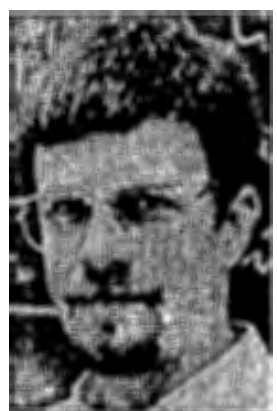

Jörg Thomas Epplen, geb. 1952 in Göppingen; 1971-1977 Medizinstudium in Freiburg (Abschluß: Promotion); 1977-1979 Ausbildungsstipendium der DFG am Institut für Humangenetik in Göttingen; 19801982 Forschungsstipendium der DFG am City of Hope Research Institute, Duarte, USA; 1982 1983 Assistant Professor am gleichen Institut; 1983-1988 Leiter der Nachwuchsgruppe „Krebsforschung“ am MPI für Immunbiologie in Freiburg (Habilitation 1987); 19881991 Leiter der Arbeitsgruppe für Molekulare Immunologie am MPI für Psychatrie in Martinsried; seit 1991 Ordinarius für Molckulare Humangenetik an der Ruhr-Universität Bochum.

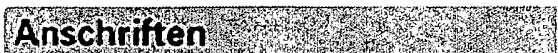

T. Lubjuhn, Arbeitsgruppe Verhaltensforschung, Fakultät für Biologic, Ruhr-Universität Bochum, Postfach 1021 48, 44780 Bochum.

Prof. Dr. M. Schartl, Physiologische Chemic I, Theodor-Boveri-Institut für Biowissenschaften, Universität Würzburg, Am Hubland, 97074 Würzburg.

Prof. Dr. J. T. Epplen, Molekulare Humangenetik, Medizinische Fakultät, Ruhr-Universität Bochum, Postfach 102148,44780 Bochum. 